\title{
Agressivitat i adolescència. Un problema social?
}

\section{Roger Martínez}

Universitat Autònoma de Barcelona. Departament de Sociologia

08193 Bellaterra (Barcelona). Spain

rms@arrakis.es

\section{Marta Rovira}

Universitat Autònoma de Barcelona. Departament de Sociologia

08193 Bellaterra (Barcelona). Spain

Marta.Rovira@uab.es

Data de recepció: setembre 2000

Data d'acceptació: abril 2001

\section{Resum}

La preocupació per l'agressivitat a les escoles de secundària ha augmentat considerablement durant els darrers anys. En aquest article, fonamentat en una recerca empírica duta a terme en instituts de secundària, intentem proporcionar eines per comprendre el fenomen de l'agressivitat com a element intrínsec en les relacions socials quotidianes a l'adolescència. Analitzem com l'agressivitat s'estructura socialment d'una manera concreta segons la localització social i cultural, especialment a partir del gènere i la classe social. També aprofundim en l'agressivitat a partir de tres dimensions: 1) les jerarquies establertes a l'escola entre els joves; 2) la segregació entre nois i noies i els seus mons de vida, i 3) la importància del control i l'autocontrol.

Paraules clau: agressivitat, adolescència, cultura juvenil, educació i gènere.

\section{Resumen}

La preocupación por la agresividad en los centros de secundaria ha aumentado considerablemente durante los últimos años. En este artículo, fomentado en base a una investigación empírica llevada a cabo en institutos de secundaria, intentamos proporcionar herramientas para comprender el fenómeno de la agresividad como elemento intrínseco en las relaciones sociales cotidianas de la adolescencia. Analizamos como la agresividad se estructura socialmente de una forma concreta según la localización social y cultural, especialmente a partir del género y la clase social. También profundizamos en la agresividad a partir de tres dimensiones: 1) las jerarquías establecidas en la escuela entre los jóvenes; 2) la segregación entre chicos y chicas y sus mundos de vida, y 3) la importancia del control y autocontrol.

Palabras clave: agresividad, adolescencia, cultura juvenil, educación y género.

\section{Abstract}

In Catalonia (Spain) there is a growing concern about agressiveness in secondary schools. In this article, based on an empirical research carried out in secondary schools, we try to provide tools to understand agressiveness as an inherent element of everyday social relations in adolescence. We analyze how agressiveness is socially structured depending on social and 
cultural position, particularly in relation to gender and social class. We also analyze agressiveness from three different dimensions: 1) school hierarchical pecking-order; 2) segregation between boys and girls and their life worlds; 3) the importance of control and selfcontrol.

Key words: agressiveness, adolescence, youth culture, education and gender.

\section{Sumari}

Introducció: el «problema» de l'agressivitat Conclusions

L'agressivitat Implicacions

Agressivitat, gènere i estructura social

Annex

L'agressivitat en la vida dels joves

Bibliografia

[...] els predicadors de la capella papal repeteixen que tantes novetats ens han de portar a la ruïna, que la humanitat viu en el present molts graons més baixa que en el passat i que s'acosta el dia de retre comptes per haver-nos deixat anar tan avall i a tan gran desordre de costums i decadència, $[\ldots]$ però he escoltat $i$ he pensat prou per saber com són de facils i d'atractius aquests sermons i tots els versos i els discursos del mateix estil, jo veig que el temps present no és pitjor que l'antic, les coses noves m’agraden més que les velles, i no crec ni que els ulls dels meus fills veuran l'apocalipsi.

Borja Papa, Joan F. Mira, p. 161-162, 1996 [1492]

\section{Introducció: el "problema» de l'agressivitat}

Durant els darrers anys ha crescut molt la preocupació per l'agressivitat a les escoles. El "problema social» de la violència és i ha estat sempre el problema dels «joves» - masculins - violents que amenacen l'ordre i la pau socials, en aquest cas a l'escola, abans als carrers. En lloc d'intentar comprendre l'agressivitat d'una manera seriosa, malgrat tot, en aquestes situacions s'acostumen a buscar explicacions precipitades, com ara la influència de la gran quantitat de violència que els joves veuen a la televisió o la pèrdua d'autoritat dels adults. Només cal fer una mirada a la història per adonar-se que aquestes explicacions amaguen més del que ensenyen. La manca de control sobre les generacions de joves $\mathrm{i}$ adolescents — o la por respecte de la seva conducta - i el "problema social» de l'agressivitat en aquest grup d'edat ja eren, per exemple, molt importants a l'edat mitjana.

Els sermons dels capellans a la Itàlia del segle XV ja anaven dirigits a reformar la conducta dels joves - i les dones-, que es consideraven moralment fràgils, mancats de restriccions i amb gustos luxuriosos i pervertits en la mane- 
ra de vestir (Coruzet-Pavan, 1997). Les gamberrades i l'agressivitat havien format part de la manera de fer dels grups de joves des de sempre, però no es van començar a combatre fins a la segona meitat del segle XV (Schlinder, 1997). Fins aleshores es preferia fer la vista grossa per tal que fossin els mateixos joves els que arreglessin les seves sortides de to entre ells. En aquest sentit, és interessant tenir en compte que sovint l'agressivitat i la violència no esdevenen un problema social quan es produeixen, sinó quan es comença a donar per descomptat que no s'haurien de produir. Durant l'edat mitjana, la violència, l'honor i la venjança havien estat elements molt importants, que a poc a poc van començar a ser objecte de condemna.

La violència sempre ha estat present no només entre els joves, sinó al propi sistema escolar. Fa unes dècades era exercida fins i tot físicament pels mateixos professors. És difícil quantificar i comparar la violència que hi ha actualment amb la que hi havia fa deu, vint o cinquanta anys, ja que la seva naturalesa ha canviat. És obvi que la disciplina a cop de regla de la postguerra pràcticament ha desaparegut, i això implica canvis molt importants en les relacions socials a l'escola. De la mateixa manera, l'atmosfera autoritària, policial i repressora dels primers anys del franquisme no té res a veure amb la realitat que experimenten els joves avui dia. No és gens clar, malgrat això, que l'agressivitat que hi havia als patis, als carrers o a la sortida de les escoles aleshores fos menor que l'actual.

També cal plantejar-se fins a quin punt el fet que la percepció que l'agressivitat a les escoles hagi augmentat és producte de l'escolarització obligatòria i comprensiva fins als setze anys, que pot haver traslladat al conjunt dels instituts unes pràctiques que abans es localitzaven als carrers o en centres molt determinats en els quals es consideraven «inevitables». Així, instituts que amb el sistema educatiu anterior gaudien del privilegi de la selecció prèvia del seu alumnat (els alumnes amb més bona disposició cap a l'escola), ara reben tot tipus d'estudiants, fins i tot aquells que amb l'anterior sistema escolar haurien deixat els estudis abans dels setze anys ${ }^{1}$.

No obstant això, no és l'objectiu d'aquest article determinar què hi ha de real en les pors que expressen les famílies, el professorat i el mateix alumnat respecte de l'agressivitat. L'objectiu és comprendre l'agressivitat com a part inherent de la vida dels joves i entendre com la seva lògica social va lligada a institucions i processos socials fonamentals, com el procés de civilització, l'estructura social, el gènere i els tipus de producció cultural.

Primerament analitzarem teòricament el concepte d'agressivitat de manera que ens permeti comprendre la realitat que estudiem. Per això haurem de trencar amb la visió intuïtiva que tenim de l'agressivitat com a "problema». En segon lloc, exposarem els resultats d'un estudi empíric sobre l'agressivitat

1. Un dels exemples de l'angoixa que poden generar les situacions incontrolades és el d'un centre d'una ciutat mitjana de Catalunya que va adoptar la «solució» d'adjudicar unes escales per als alumnes de primer cicle i unes altres per als alumnes de l'antic BUP perquè no coincidissin en els passadissos. 
conduït a diversos centres escolars. Analitzarem els resultats d'una enquesta i de diversos grups de discussió i entrevistes en profunditat en relació amb el gènere i l'estructura social, d'una banda, i a tres dimensions que hem establert, de l'altra.

\section{L'agressivitat}

El nostre punt de partida és defugir qualsevol concepció alarmista de l'agressivitat i provar de comprendre-la més a bastament. Com dèiem, l'agressivitat és viscuda només com un problema quan és més visible, quan provoca conflictes, desordre, quan posa en qüestió la legitimitat de les normes socials oficials. No s'acostuma a considerar, en canvi, tota l'agressivitat que queda amagada en les relacions personals i encara menys en les relacions institucionals. Tampoc no es veu amb els mateixos ulls l'agressivitat d'uns joves al centre de la ciutat que en determinats barris periferics, ni la d'uns adolescents al mig del carrer que l'agressivitat "legítima» de la policia o l'agressivitat indirecta que exerceixen determinades estructures de poder.

\section{Ordinari i extraordinari}

Des d'una perspectiva sociològica és important diferenciar analíticament l'agressivitat «real» de l'agressivitat «socialment percebuda» (tot i que a la pràctica la frontera entre totes dues és molt difícil d'establir). El fet que s'assenyali l'agressivitat provocada per determinats col-lectius o perfils socials ens indica, de fet, qui té el poder per definir allò que és (gratuïtament) agressiu en la nostra societat i quines conductes són motiu de reprovació. Que augmenti la preocupació per l'agressivitat pot voler dir que ha augmentat l'agressivitat, però també que ha augmentat la reprovació social de l'agressivitat. Ja hem dit com la societat de l'edat mitjana era una societat molt més violenta que la nostra, però no existia la preocupació per l'agressivitat que tenim nosaltres. Distingint entre agressivitat "real» $\mathrm{i}$ "socialment percebuda» no només adquirirem perspectiva històrica, sinó també social, ja que ens permetrà fixar-nos en com la definició de l'agressivitat depèn del poder i de la posició a l'espai social d'aquells que l'exerceixen i d'aquells que la denuncien.

Per exemple, per un gitano defensar el seu honor pot comportar una manera de fer reprovable als ulls d'una persona paia, sobretot si és de classe mitjana. De la mateixa manera, un jove cap rapat pot considerar que si no respon a una agressió física perdrà la seva integritat, mentre que un altre jove voluntari en una $\mathrm{ONG}$ contra el racisme pot pensar que això no té cap sentit. $\mathrm{O}$ pensem en com l'agressivitat entre joves als carrers es considera relativament "normal», mentre que la mateixa conducta a les escoles és un "greu problema social».

$\mathrm{Si}$ analitzem detingudament l'agressivitat extrema, aparentment "gratuïta», veurem com darrere hi ha no només raons perfectament intel-ligibles, sinó també relacions socials, regles i pautes de comportament que formen part de la realitat de cada dia. Aquestes relacions socials i aquestes pautes de compor- 
tament, lluny de ser anomalies individuals, estan estructurades socialment i formen part de la vida quotidiana dels adolescents. Per tant, res de "gratuïta», en el sentit de deslligada de les relacions socials quotidianes. No acceptem aquell punt de vista que veu l'agressivitat que es manifesta a les escoles, a les discoteques o al barri només com un fenomen sorgit de la marginalitat, del rebuig accentuat a la institució escolar i de la patologia individual. És a dir, com quelcom «extraordinari». Partim de la base, en canvi, que l'agressivitat no és un element aliè a les relacions socials. Per tant, allò que ens interessa és com es manifesta durant l'adolescència i la joventut, quines formes pren, i com s'estructura socialment segons el gènere i la posició en l'estructura social.

\section{Definició}

Primer de tot, trencarem amb la indefinició del mateix concepte. D'ara en endavant, entendrem per agressivitat no només l'agressivitat física, sinó tota conducta que vol fer mal o ferir una altra persona. Aquesta és una definició molt comuna, que tanmateix no té en compte, i que tampoc considerarem aquí, l'agressivitat com a mecanisme de defensa davant dels altres. El que ens interessa analitzar aquí és l'agressivitat com a coacció o maltractament exercida externament sobre una persona o un grup. És difícil trobar un concepte que defineixi alhora totes les formes possibles d'agressivitat i que al mateix temps no inclogui significats socials molt connotats. Per exemple, la paraula anglesa bullying ha servit per introduir una nova perspectiva de l'agressivitat a l'escola, que té en compte tant les agressions físiques com les agressions no físiques que tenen la intenció d'intimidar, tiranitzar o obligar algú a fer alguna cosa amb amenaces. Tant en català com en d'altres llengües llatines el terme més utilitzat és el de violència (violencia, violence). Els termes agressió i agressivitat poden ser útils per desmarcar-se de la connotació de desordre social que conté el de violència. Tanmateix, per aconseguir certa claredat conceptual, pensem que és millor referir-nos a diversos tipus d'agressivitat. Així doncs, seguint Owens i MacMullin (1995), distingim entre tres principals formes d'agressivitat:

1) L'agressivitat fisica, que consisteix a donar cops o bufetades, fer trabanquetes, robar objectes, donar empentes o estirar.

2) L'agressivitat verbal directa, que consisteix a cridar, insultar, amenaçar algú de fer-li mal, burlar-se'n, o fer servir noms despectius per referir-se a algú.

3) L'agressivitat indirecta, que consisteix a excloure algú del grup, fer-se amic d'algú altre com a revenja, ignorar, rumorejar, explicar històries dolentes sobre algú que són falses, planejar secretament com empipar algú, explicar secrets dels altres, malparlar, escriure notes desagradables, criticar el pentinat o la manera de vestir o intentar que els altres sentin disgust per algú.

Entesa així, és obvi que l'agressivitat sempre ha estat present en la història de la humanitat i que, lluny de ser un fenomen «extraordinari», forma part de la nostra vida de cada dia. És difícil trobar cap tipus de relacions socials que 
no impliquin, en un sentit o altre, algun tipus d'agressivitat, si bé és cert que en cada societat aquesta agressivitat es canalitza a través de formes socials específiques. El fet que l'agressivitat es produeixi al carrer no ens ha de preocupar més, des d'un punt de vista sociològic, que el fet que es produeixi en el marc mateix de les estructures socialment legítimes com ara l'escola. Així, socialment no es retreu a un executiu o a un esportista que siguin «agressius». En el cas dels policies o els militars, fins i tot s'espera d'ells que actuïn amb contundència quan la situació ho demani. Es considera il.legítim, en canvi, que un jove es defensi a garrotades de la violència simbòlica de la presència policial o d'una sovint alienant cultura escolar. Les estructures socials dominants són les que tenen la capacitat i el poder per emmascarar l'agressivitat o presentarla com a legítima. I com veurem més endavant, l'agressivitat no és la mateixa, ni s'expressa de la mateixa manera, en tots els sectors socials.

Des del nostre punt de vista, doncs, cal entendre l'agressivitat com un fenomen que té en la violència extrema només la seva manifestació més visible. Podríem dir que representa només la punta de l'iceberg.

\section{L'agressivitat com a fenomen cultural $i$ transcultural}

Abans d'iniciar l'anàlisi empírica, volem apuntar dues qüestions. En primer lloc, l'agressivitat no és un fenomen aïllat ni específic d'algunes societats. L'agressivitat és un fenomen transcultural que es manifesta en totes les esferes socials i en tots els contextos culturals. Alguns estudis (Rivers i Smith, 1994; Hines i Fry, 1994; Owens i MacMullin, 1995; Rigby i Slee, 1995) fins i tot indiquen que el desenvolupament de l'agressivitat durant la infancia i l'adolescència segons el gènere presenten constants transculturals. És més, la preocupació per l'augment de l'agressivitat a les escoles es dóna a la majoria de països occidentals.

En segon lloc, com dèiem, l'agressivitat no s'expressa de la mateixa manera a tot arreu ni en tots els contextos socials. Fins i tot en la conducta més agressiva, aquella en la qual aparentment «no hi ha normes que valguin» perquè «es perd el cap», presenta diferències segons les cultures. Si no seria difícil explicar que a certes parts del món es comencin a tirar trets per una mala mirada, mentre que a d'altres els trets només es disparin en situacions molt extremes. És molt interessant, en aquest sentit, com aquells joves acostumats a barallar-se, després d'explicar com en una baralla han perdut el cap, a continuació comenten amb indignació com el seu oponent no ha seguit el mateix codi ètic que ells durant la baralla. És a dir, que l'aparent pèrdua de control que representa l'agressivitat extrema pràcticament sempre està sotmesa a uns controls culturals in-corporats. Aquests controls culturals són els que canalitzen i donen una forma determinada a l'agressivitat que és present a totes les societats.

En aquest article, per tant, pretendrem copsar tots dos vessants: d'una banda, el seu caràcter inherent a la nostra condició humana i, de l'altra, la importància de la cultura en la seva articulació concreta. L'agressivitat no només pren formes diferents segons les cultures, sinó també dintre d'una mateixa 
cultura. No es pot deslligar, de fet, d'elements socials tan importants com el procés de civilització, l'estructura social, el gènere i les relacions de poder.

\section{Tècniques utilitzades}

El punt de partida serà un estudi empíric que consisteix en una enquesta realitzada a dos instituts sobre les agressions que pateix l'alumnat de segon d'ESO ${ }^{2}$ i en catorze grups de discussió i nou entrevistes en profunditat. Pràcticament tot el material fou recollit en el marc del Projecte Arianne, en el Programa de Coeducació de l'ICE-UAB, finançat per la Comissió Europea. Els grups de discussió es van fer a set centres ${ }^{3}$, un de primària (amb alumnes d'onze i dotze anys) i sis de secundària (amb alumnes de quinze anys). Entre aquests centes n'hi ha dos que són predominantment obrers, dos centres amb orígens socials diversos, però amb fills d'empleats que podem considerar. A cada centre es va organitzar un grup amb noies i un altre amb nois. En els grups de discussió es va preguntar sobre la relació amb l'altre sexe, les tasques domèstiques, l'agressivitat, $\mathrm{i}$ altres qüestions. Les nou entrevistes es van fer a nois de secundària (ESO, BUP i FP) en un centre predominantment - però no exclusivamentobrer, i es va discutir amb els entrevistats sobre l'agressivitat, els estudis, i la relació amb les noies i els pares. Finalment, també hem utilitzat material d'un estudi sobre el gust juvenil fet a Terrassa (Martínez i Pérez, 1997).

\section{Agressivitat, gènere i estructura social}

L'enquesta que vam realitzar en dos instituts de secundària tenia la intenció de recollir la quantitat d'agressivitat percebuda pels adolescents en la vida diària. Això té un inconvenient: l'enquesta introdueix una sèrie de qüestions que normalment no es relacionen amb el concepte d'agressivitat. Per tant, l'enquesta acabava fent la funció de sensibilització en relació amb aquest tema, ja que demanava als adolescents que reconeguessin com a agressius comportaments que normalment no són considerats com a tals (tot i així, l'enquesta no aborda ni l'agressivitat indirecta a partir dels «rumors» ni les possibles agressions del professorat).

Tanmateix, això representa una certa novetat en la manera d'abordar el tema en els instituts, ja que té en compte qüestions importants. El fet mateix que ens referim a l'agressivitat en un sentit ampli, ens permet fer un salt en la

2. L'enquesta la van respondre 177 alumnes de dos instituts (un de Castelldefels i l'altre de Vilafranca del Penedès) en el marc del Projecte Arianne del Programa de Coeducació de l'ICE-UAB (per a més informació vegeu l'informe final). L'enquesta, que els alumnes i les alumnes van contestar a les classes de tutoria de segon d'ESO durant el curs 1997-1998, els preguntava si havien estat agredits, com, quan, on i per qui, entre d'altres coses.

3. Un centre de primària de Tomelloso (Castella), els dos instituts on també es va fer l'enquesta i quatre centres de secundària de Sabadell. Aquests últims grups de discussió es van fer en el marc d'un estudi sobre el sexisme a Sabadell. 
concepció «habitual» del tema, i oferir al professorat i al mateix alumnat dades concretes sobre una qüestió que queda sovint amagada en la dinàmica quotidiana dels instituts. D'altra banda, l'enquesta esdevé un mitjà d'expressió, tot i les limitacions, per a l'alumnat que és víctima de les agressions.

\section{Tipus d'agressivitat}

A l'enquesta vam preguntar concretament sobre l'agressivitat física i l'agressivitat verbal directa. També vam incloure una pregunta sobre un dels tipus d'agressivitat indirecta: l'exclusió del grup d'amics o d'amigues. Els resultats mostrats a la taula 1 constaten clarament com l'agressivitat forma part de la realitat quotidiana de molts adolescents, encara que no sempre és percebuda com a tal. Malgrat que a la pregunta de si havien patit alguna agressió durant l'últim mes gairebé la meitat dels alumnes $(41,3 \%)$ va respondre afirmativament, en les preguntes sobre el tipus d'agressió (taula 2) i altres aspectes les respostes superen aquesta xifra. Per tant, podem suposar que molts adolescents que han respost negativament a la primera pregunta o que no l'han respost, ho fan perquè no consideren com a agressions determinades conductes. En canvi, quan se'ls pregunta explícitament sobre aquestes conductes, afirmen haver-les patit.

El tipus d'agressions més freqüents (taula 2) són sobretot agressions verbals i burles. És a dir, agressions verbals directes que normalment suposen una intimidació de la víctima (insults, menyspreus, etc.). Aquest tipus d'agressivitat és la més quotidiana i la menys «visible» per part del professorat o dels adults en general. També la que no se sol considerar com «agressió», malgrat que pot ferir tant o més que una agressió física, i sovint és un mecanisme de dominació.

Taula 1. Freqüència de les agressions en un mes.

\begin{tabular}{lr} 
Cada dia & $0,5 \%$ \\
Moltes vegades & $4,6 \%$ \\
Bastants vegades & $1,0 \%$ \\
Algunes vegades & $35,2 \%$ \\
Cap vegada & $41,4 \%$ \\
No contesten & $17,3 \%$ \\
\hline
\end{tabular}

Taula 2. Tipus d'agressions més freqüents.

$\begin{array}{ll}\text { Agressió verbal } & 69,4 \% \\ \text { Burla } & 54,1 \% \\ \text { Agressió física } & 36,3 \% \\ \text { Al material de l'alumne/a } & 38,2 \% \\ \text { Agressió escrita } & 20,4 \% \\ \text { Exclusió del grup } & 18,4 \% \\ \text { Agressió a la roba } & 12,3 \% \\ \text { Robatori de diners } & 10,8 \%\end{array}$


Taula 3. Lloc on es produeixen les agressions.

\begin{tabular}{lr} 
Aula & $53,3 \%$ \\
Carrer & $42,3 \%$ \\
Passadís & $23,4 \%$ \\
Menjador & $4,6 \%$ \\
Lavabo & $4,0 \%$ \\
Altres llocs (pati) & $51,6 \%$ \\
\hline
\end{tabular}

Però l'enquesta ens dóna com a resultat també un alt percentatge d'agressions físiques, tot i que, pel que expliquen els mateixos adolescents, aquestes solen ser "petites» agressions: empentes, trabanquetes, etc. Hi ha uns altres tipus d'agressions que indiquen que l'ambient dels instituts pot esdevenir força «hostil» per a l'alumnat: agressions al material propi, a la roba, als diners, agressions escrites (és a dir, que queden). Segons aquestes dades, podem dir que els maltractaments que pot rebre l'alumnat van molt més enllà del que la mateixa comunitat educativa arriba a percebre mai —més enllà, per descomptat, de les agressions més «dures» i aparentment més «gratuïtes». D’altra banda, el tipus d'agressió més indirecta que hem inclòs a l'enquesta, l'exclusió del grup d'amics o d'amigues, es dóna en el 18,4\% dels casos.

L'alumnat assenyala en un 53,3\% dels casos que l'aula és el lloc on han patit les agressions (taula 3). En canvi, el professorat amb qui hem parlat percep molt més l'agressivitat en els passadissos (és a dir, fora del seu control directe) - tot i que els alumnes només indiquen el passadís com a lloc on es produeix l'agressió en el 23,4\% dels casos-. El carrer, com podem veure, també és un dels llocs on es produeixen més agressions, en part provocades per enfrontaments entre bandes a les portes de l'institut.

Aquestes són les dades «brutes», que si bé ens donen una idea de la dimensió de la qüestió, no ens diuen res del seu «sentit» ni ens ajuden a comprendre com s'estructura socialment. En el que resta d'aquest apartat, analitzarem com aquesta agressivitat s'estructura segons el gènere i la classe social.

\section{Gènere i classe social}

Si desglossem les dades per sexe (taules 4 i 5), veiem que no hi ha diferències gaire importants, però sí algunes que val la pena remarcar. A la taula 4 veiem que el percentatge de nois que reben agressions sovint («moltes vegades») és superior al de noies. D'altra banda, el percentatge de noies que no han rebut agressions durant l'últim mes és superior al de nois ("cap vegada»). Per tant, els nois són una mica més objecte d'agressions que les noies. I com podem veure a la taula 5 , els nois també reben més agressions físiques que les noies (el $48,1 \%$ dels nois ha rebut una agressió física, i «només» el 34,8\% de les noies).

$\mathrm{Si}$ analitzem com intervenen nois i noies en les diverses situacions agressives que es produeixen (taula 6), trobem una tendència general: les agressions 
Taula 4. Freqüència de les agressions que han patit nois i noies en un mes.

\begin{tabular}{lrrrr}
\hline & \multicolumn{2}{l}{ Nois } & \multicolumn{2}{c}{ Noies } \\
\hline Cada dia & 1 & $(100 \%)$ & & 0 \\
Moltes vegades & 5 & $(55,6 \%)$ & 4 & $(44,4 \%)$ \\
Bastants vegades & 0 & $(0 \%)$ & 2 & $(100 \%)$ \\
Algunes vegades & $30(43,5 \%)$ & $39(56,5 \%)$ \\
Cap vegada & $38(46,9 \%)$ & $43(53,1 \%)$ \\
\hline
\end{tabular}

Taula 5. Percentatge de nois i noies que pateixen cada tipus d'agressió.

\begin{tabular}{lllr}
\hline & \multicolumn{2}{c}{ Nois } & \multicolumn{2}{c}{ Noies } \\
\hline Agressió verbal & $63(77,7 \%)$ & $73(77,7 \%)$ \\
Burla & $50(63,3 \%)$ & $56(60,9 \%)$ \\
Agressió física & $39(48,1 \%)$ & $32(34,8 \%)$ \\
Al material de l'alumne/a & $35(43,7 \%)$ & $40(47,4 \%)$ \\
Agressió escrita & $13(16,2 \%)$ & $27(29 \%)$ \\
Exclusió del grup & $16(20,5 \%)$ & $20(22 \%)$ \\
Agressió a la roba & $13(16,5 \%)$ & $11(12,2 \%)$ \\
Robatori de diners & $10(12,8 \%)$ & $11(12,1 \%)$ \\
\hline
\end{tabular}

Taula 6. Qui agredeix.

$\begin{array}{ll}\text { Un noi } & 33,7 \% \\ \text { Una noia } & 21,4 \% \\ \text { Un grup de nois } & 48,4 \% \\ \text { Un grup de noies } & 31,6 \%\end{array}$

Taula 7. Qui agredeix segons el sexe de la víctima.

\begin{tabular}{lrc}
\hline & Masculí & Femení \\
\hline Grup de nois & $35,3 \%$ & $25,7 \%$ \\
Grups de noies & $8,9 \%$ & $30,9 \%$ \\
Noi & $25,8 \%$ & $16,8 \%$ \\
Noia & $6,9 \%$ & $11,4 \%$ \\
\hline
\end{tabular}

són sobretot produïdes per nois en grup $(48,4 \%)$. Alhora, a la taula 7 podem veure que les noies solen agredir molt més a persones del mateix sexe que no pas als nois. Mentre que els nois no són gaire agredits per noies, aquestes sí que són víctimes d'agressions, tant per part de nois com de noies.

L'agressivitat no és un fenomen aliè a la variable del gènere. Les dades ens indiquen que en els tipus d'agressivitat tractats a l'enquesta hi ha una posició dominant dels nois respecte de les noies, les quals són, en general, víctimes però no culpables de les agressions entre els dos sexes. En aquest sentit, alguns autors apunten que l'agressivitat directa — física i verbal- és un element central en la construcció de la identitat masculina. Aquesta agressivitat directa és 
fonamental per al que Connell (1995) anomena «masculinitat hegemònica», que es defineix en oposició a la feminitat i a d'altres masculinitats.

Però la masculinitat estereotípica i hegemònica no és l'única existent: com emfasitza Mac an Ghaill (1996), els nois sempre opten entre diverses masculinitats disponibles, de manera que les identitats masculines no agressives esdevenen normalment subordinades, i sovint es poden afirmar com a tipus de resistència o adaptació a la masculinitat hegemònica (Pattman, 1998: 128). Diversos entrevistats, per exemple, ens van explicar com davant de la seva inhabilitat per pegar-se o mantenir la posició físicament, havien buscat altres maneres de mantenir la dignitat, per exemple fent mal amb les paraules.

Les dades mostren, malgrat tot, que les noies també participen del joc de l'agressivitat, tot i que semblen indicar que ho fan de manera diferent. En la seva recerca, Owens i MacMullin (1995) van comprovar com les dones tendien a manifestar la seva agressivitat a través d'estratègies indirectes, com ara marginant, malparlant, escampant rumors, etc. En els nostres grups de discussió amb nois i noies - per separat - de quinze anys de sis instituts de secundària a Vilafranca, a Castelldefels i a Sabadell, hem pogut aprofundir en les pautes i les regles de gènere i en com són interioritzades pels adolescents. En parlarem quan analitzem la segregació dels mons de vida dels nois i de les noies.

L'altre element estructural que cal tenir en compte és l'estructura social. Segons la posició en l'estructura social, el model de masculinitat varia. Els nois de famílies privilegiades en l'estructura social tendeixen amb més freqüència a desmarcar-se de la violència física $i$, en general, a rebutjar "pegar-se» — com a mínim en el seu discurs- . Prefereixen altres estratègies per posicionar-se (els noms de tots els entrevistats han estat canviats):

MiQueL: Home, és millor arreglar-ho amb la boca, no amb punys. És més civilitzat. De l'altra manera, a veure, és més..., o sigui..., no s’ha de per què arribar sempre als punys, sinó que s'ha de saber arreglar parlant...

Conceptualment podem distingir una línia que va de l'agressió més latent i simbòlica (excloure) a l'agressió més física (pegar). Els dos pols corresponen, en línies generals, als gèneres femení i masculí, respectivament, però també als extrems dominants i dominats de l'estructura social. Diferents estudis (Rivers i Smith, 1994; Hines i Fry, 1994; Owens i MacMullin, 1995; Rigby i Slee, 1995) han vist com, a diferents societats i cultures, les noies desenvolupen abans - després d'uns primers anys ens els quals es comporten igual que els nois - aquestes formes indirectes d'agressivitat, que requereixen més autocontrol i elaboració que les directes. Així, es dóna la paradoxa que l'autocontrol de l'agressivitat més òbvia i la seva transformació en formes més elaborades i complexes és característic del gènere femení, que és el gènere dominat, $\mathrm{i}$ dels homes de les classes mitjanes i altes, que és el sector social dominant.

Il.lustrarà perfectament aquesta idea aquesta citació d'un noi que, després d'anar tota la vida a una escola pública d'un barri obrer, acaba d'entrar en una escola privada de secundària on predominen els alumnes de classe mitjana: 
RICARDO: [a la nova escola] son más listos, prefieren no hacerse daño, no mancharse las manos, y..., no sé, te hacen daño de otra manera, a lo mejor hablando mal de ti, marginándote, no sé..., los otros no, los otros te pegan y así quedan ellos como reyes, los más fuertes.

Així, segons la posició en l'estructura social, les formes de relacions socials varien. Als diversos llocs hi trobem les diferents masculinitats, però el que canvia són les formes normatives o dominants de relacions socials. Com diu Paul Willis (1998), hi ha barris, centres escolars i ambients en els quals el perill de l'agressió física és respira en l'ambient. I aquests ambients normalment es corresponen a posicions més baixes en l'estructura social. En aquests entorns l'agressivitat directa, física i verbal és més habitual, la qual cosa condiciona les cultures masculina i femenina en les quals se socialitzen els individus —en aquests contextos, per exemple, les noies estan més acostumades no només a acceptar, sinó fins i tot a esperar conductes més agressives per part dels nois. La posició en l'estructura social, per tant, podem dir que prefigura un habitus $\mathrm{i}$ unes formes de relacions socials en els quals l'agressivitat física hi és més o menys present.

El fet que en certs barris i centres escolars l'agressivitat directa (física i verbal) es respiri a l'ambient fa que les diferents masculinitats i feminitats es manifestin de maneres diferents. En instituts on no és així, no és necessari exercir l'agressivitat física i verbal directa per aconseguir el respecte (la qual cosa facilita l'existència dels joves amb una masculinitat no hegemònica). Quan l'ambient és agressiu, en canvi, l'agressivitat física es presenta amb més força com una necessitat derivada del mateix context de relacions. Saber respondre a les agressions directes i demostrar que un no és "feble» és una necessitat imposada pel joc de l'agressivitat. Aquesta citació d'un grup de discussió amb nois de classe mitjana proporciona un exemple de com una persona pot ser obligada a entrar en el joc de l'agressivitat encara que no li agradi, i distingeixen entre els que hi juguen «per diversió» i els que ho fan "perquè els provoquen»:

\section{ARNAU: És que és per qualsevol tonteria.}

JORDI: Al meu centre per exemple, bueno, hi ha molts quillos ${ }^{4}$ d'aquests i sempre estan molestant, i són uns pesats, no?, i primer comencen a fer així, després un copet, i t'acabes enrabiant i barallant.

ARNAU: Clar! I si tu ets un d'aquests que saltes de seguida i li tornes ja està JORDI: Llavors ja vénen tots els grups, no? Si tu li fots a algú, tu el guanyes posem, però llavors saps que no ho pots fer perquè té amics, bueno, tota una penya i que te la poden fotre.

ARNAU: S'ho passen bé, per diversió.

4. «Quillo» és una paraula d'argot utilitzada per nois de classe mitjana i alta per referir-se a nois de classe obrera amb conductes més agressives, associat també a diferents estils en el vestir, el pentinat, la música, etc. En ambients més obrers, en canvi, s'acostuma a utilitzar per referir-se a un estil estereotipat com a gitano: cabells llargs, camisa oberta, cadenes ostentoses, música flamenca i rumba, etc. 
A les parts mitjanes i altes de l'estructura social és més important saber lluitar en l'esfera de l'agressivitat indirecta: la lluita es produeix més simbòlicament, a través del menyspreu, la marginació, la denigració. Per ells, l'agressivitat física tendeix a ser justament un tret distintiu del no ser. Com deia en Miquel més amunt, «És millor arreglar-ho amb la boca. És més civilitzat». Així, aquells que tenen la capacitat de "parlar», és a dir, de posicionar-se i de posicionar els altres en l'espai social per mitjà del llenguatge, són els "civilitzats». L'agressivitat simbòlica és aquella que no es mostra com a tal. D'aquesta manera, seguint Bourdieu (1980), podem dir que les classes dominants tenen la capacitat per emmascarar la seva agressivitat, justament amb un llenguatge que distingeix entre "civilització» $\mathrm{i}$ «barbàrie», $\mathrm{i}$ que distingeix així les posicions socials presentant-les com a comportaments correctes i incorrectes. La cultura escolar reforça en bona mesura aquesta realitat: l'agressivitat verbal no és penalitzada com ho és l'agressivitat física, tot i que és utilitzada a bastament pels adolescents en els instituts.

Des de determinades posicions dominades, la consciència que tenen els fills d'obrers de ser diferents dels nois de classe mitjana els porta a reafirmar la seva masculinitat a partir de mecanismes com ara l'agressivitat física (Willis, 1981). Willis explica com els nois contraescola que estudià —els col-legues, els que s'oposen als professors i a l'escola en general-s'oposen a la cultura escolar "civilitzada» perquè, en realitat, aquesta cultura escolar meritocràtica va en contra dels interessos dels «col-legues» com a col-lectiu. L'agressivitat física és, en aquesta oposició, una manera de demostrar que no s'és com «els altres», els acomodats al sistema o els nois de casa bona.

Segons la classe social, en definitiva, varia la construcció del gènere masculí i femení - i de les relacions de poder entre les diferents masculinitats i feminitats-. L'estructuració social de l'agressivitat segons el gènere i la classe social, però, no és lineal. No podem dir que els nois de classe mitjana no exerceixin l'agressivitat directa, $\mathrm{i}$ encara menys que tots els nois de classe obrera ho facin. Els gèneres i les relacions entre gèneres són molt més complexes que tot això. Per això volem estendre l'anàlisi a través de tres dimensions que ens ajudaran a comprendre millor el fenomen i, sobretot, a posar-lo en relació amb altres elements fonamentals. Aquestes dimensions són: 1) les jerarquies que s'estableixen entre els adolescents en les seves relacions cara a cara; 2) la segregació entre el món de vida femení i el món de vida masculí, així com les formes de contacte entre els dos mons; 3) la relació entre els diferents tipus d'agressivitat i l'autocontrol, així com la seva relació amb la transició a la vida adulta, l'estructura social i el procés de civilització occidental.

\section{L'agressivitat en la vida dels joves}

\section{Microjerarquies}

En sociologia, utilitzem el concepte de "grup d'iguals» per referir-nos al grup d'amics, que, en estar units per amistat, són «iguals». L'anàlisi de les relacions 
a partir del fenomen de l'agressivitat ens mostra que aquesta igualtat és almenys sospitosa. Les posicions de dominació, de jerarquització, no són alienes a les relacions entre adolescents. Com en la majoria de relacions socials, en la vida dels adolescents la competència - implícita o explícita - és un element molt important. No volem dir amb això que no existeixin també relacions socials cooperatives - ans al contrari, també són una constant històrica-, sinó senzillament que les competitives només rarament hi són absents. També als instituts. Per molt bé que es portin entre ells els alumnes d'un institut, sempre hi haurà enveges, jerarquies i distincions. I per mantenir-les o canviar-les, conscientment o inconscientment, sovint s'utilitza l'agressivitat (física, verbal o indirecta).

Producte d'aquesta competència i d'aquestes lluites — repetim, sovint de manera irreflexiva- es crea una relació de «dominació social» que es pot definir com el prestigi social, la influència i la capacitat d'atraure l'atenció i la deferència dels altres, l'accés a privilegis i a un tracte respectuós (Parkhurst i Hopmeyer, 1998: 127). Durant l'adolescència, gran part de les activitats dels joves estan encaminades a guanyar i protegir un grau satisfactori de «dominació social», i és en aquest sentit que cal entendre moltes de les bromes, les burles, les amenaces $\mathrm{i}$ els «jocs» agressius. Un bon indicador per conèixer la «dominació social» d'un alumne és saber amb quina regularitat és objecte d'agressions, físiques o verbals.

MarC: Però allò, «no me pises...». Per tonteries.

JOAN: Anar dient sempre coses a la gent.

MARC: Sentir-te superior, insults, que se te'n riguin, que et deixen fet pols...

ORIOL: Prepotència, també. Coses que et fan mal.

ESTEVE: Més que res és en conya, però hi ha vegades que...

ORIOL: Però hi ha gent que ho fot amb mala llet.

ENT: I qui ho fa això?

ORIOL: Aquest capullo.

MARC: Eh! [riures].

ORIOL: Jo he vist molt poques noies que se'n fotin de la gent així, perquè sí. El que he vist molt és nois. Els nois, com sempre, són els que se'n foten de la gent i...

Aquesta citació, a banda d'apuntar al fet que la competència entre nois i noies és diferent, ajuda a comprendre fins a quin punt és important mantenir una posició acceptable en aquesta jerarquia, ja que és la manera d'evitar ser objecte d'aquestes burles, insults, provocacions i fins i tot agressions físiques. Per molt que un jove no sigui en absolut partidari de l'agressivitat, sovint es veu abocat a entrar en el joc per assolir un nivell acceptable de respecte.

A banda d'aquesta definició negativa de la dominació social com a no ser objecte d'agressions, hi ha una definició positiva que es basa en l'accés a uns recursos escassos (tot i que no són faves comptades, ja que segons si les formes de relacions socials són més cooperatives o competitives, hi haurà més o menys recursos a repartir): amistat, popularitat, estatus, parella, sexe, diversió, respecte, admiració, etc. 
Hi ha un altre factor fonamental en les relacions socials: la pertinença a un grup i les dinàmiques de lideratge. Aquest és precisament un dels aspectes que marquen sovint la vida quotidiana dels instituts. Els adolescents i les adolescents formen els seus grups d'afins entre els membres de la classe, del curs, o amb gent d'altres instituts. La dinàmica de relació entre grups pot ser més o menys conflictiva, segons els gustos i els disgustos que comparteixin en el marc de la cultura juvenil. La presència d'un noi que utilitzi les agressions verbals o físiques, per exemple, per remarcar el seu lideratge, també afecta les relacions entre els grups d'adolescents. Posicionar-se com a membre del grup «agressiu» implicarà compartir la seva manera de fer, reforçant així la identitat del grup i de retruc la dels seus membres. És així com s'explica que molts joves només actuen de manera agressiva en grup, però no quan estan sols. Les situacions conflictives sovint es produeixen a partir dels grups i de la identificació en grups de joves, tal com explica aquest adolescent.

ANTONIO: Cuando no se llevan bien, el que sale perdiendo siempre es el «guarro» el «tirao»..., no sé, es que se lo dicen ellos, es como me llamaban a mí, ¿no? O sea..., yo creía que iba como una persona normal, ¿̨no? y aún lo creo que voy como normal. No soy nadie, no soy ni heavy, ni pelao ni nada. Y me viene un pelao y se mete conmigo y el que sale perdiendo soy yo, ¿por qué? Porque si le meto un bofetón, que no es racional, si le meto un bofetón, me viene ahí con todos sus coleguillas y..., me vienen ahí y me matan.

És en aquest context que l'agressivitat als instituts comença a prendre forma com a element inherent a la vida quotidiana dels joves, tot i que no és l'única via a través de la qual s'ordena el que podem anomenar «espai social juvenil», és a dir, el conjunt de jerarquies i distincions que determinen la posició de cadascú en el complex joc d'interaccions socials entre joves. La capacitat de fer riure, el gust musical i la manera de vestir, la lleialtat, la consideració, l'atractiu i l'aspecte físic en general, l'habilitat en els esports, la conducta infantil o adulta i molts elements més també poden ser importants segons el context.

També és fonamental l'ús que es fa dels objectes i materials culturals — música, roba, bars, discoteques, cinema - proporcionats pel mercat, ja que mediatitza aquestes relacions socials. En primer lloc, perquè la manera d'utilitzar aquests materials és un dels elements que ajuda a situar-se en les jerarquies i distincions. És a dir, que allò que s'acostuma a anomenar consumisme irracional dels joves és, en gran part, la resposta a la necessitat de ser acceptat i, com a resultes d'això, de tenir confiança en un mateix (Miles i altres, 1998: 92). I, en segon lloc, perquè els materials proporcionats pel mercat mediatitzen les relacions socials, ja que les diferents posicions a l'espai juvenil corresponen a diferents tipus de consum, i per tant són importants a l'hora de fer visibles i delimitar les diferents posicions a l'espai social juvenil.

Òbviament, és molt diferent assolir una posició de respecte a través del consum de música i de roba que no pas fer-ho a través de l'agressió física, de la mateixa manera que és molt diferent ser popular perquè s'és atent i simpàtic amb tothom que ser-ho perquè s'insulta a tothom i ningú s'atreveix a tornar- 
s'hi. Per això les jerarquies de popularitat varien segons com s'analitzen: els resultats són diferents segons si es pregunta quins estudiants agraden més o quins estudiants són més populars. I per això les jerarquies que s'estableixen entre els joves són molt complexes. Segons el context, el pes d'un tipus de popularitat o de l'altre seran diferents.

En aquestes jerarquies i en aquest espai social juvenil, a més, també hi estan reflectits el gènere i la classe social. En un institut on la majoria d'estudiants són de classe obrera, entre els nois la duresa tendirà a ser més important per mantenir una posició de dominació social que no pas en un institut de classe mitjana, en el qual l'agressivitat indirecta tendirà a ser més important.

I, de la mateixa manera, la manera de crear les jerarquies entre els nois és diferent que entre les noies. Els nois tendeixen a anar en grups amb jerarquies internes segons duresa, capacitat per anar amb noies atractives - i generalment com més millor-, capacitat de fer riure, etc. Les noies, en canvi, tendeixen més a agrupar-se amb una o dues millors amigues i tenir unes relacions més íntimes, per la qual cosa l'agressivitat pren altres formes. Això ens dóna peu a introduir la segona dimensió: la separació entre els mons de vida dels nois i de les noies.

\section{Segregació de gèneres i agressivitat}

La separació de nois i noies en escoles diferents és vista, a Catalunya, com un anacronisme. Considerem que la convivència entre els sexes a les escoles és un fet natural, tot i que presenta problemes. Si ho mirem amb deteniment, malgrat això, ens adonarem sense gaires dificultats que, a la pràctica, nois i noies segueixen creixent i socialitzant-se en mons relativament segregats. No és fins l'adolescència quan apareix l'interès pel sexe i per l'amor, que tots dos mons comencen a obrir-se l'un a l'altre. Aquesta obertura, això no obstant, no és senzilla, i per a la majoria és una font de maldecaps.

Un noi entrevistat afirmava que «Eso sí, hace falta ser lanzado con las chavalas». Si cal «ser lanzado» és perquè cal trencar alguna cosa. Tots els nois entrevistats veuen les noies - menys un que diu que senzillament no es relaciona amb elles - com a diferents dels nois, com si estiguessin «en un mundo cerrado» amb normes i pautes de comportament pròpies. A alguns els sembla malament que hi hagi poca relació entre ells i elles, i ho atribueixen a una barrera invisible, que no saben com superar. Només uns pocs privilegiats tenen facilitat per trencar aquesta barrera. Tot i així, aquests també segueixen pensant que les noies són molt diferents d'ells.

Per entendre fins a quin punt el món dels nois i el món de les noies estan segregats, fixem-nos en una activitat tan corrent com jugar a futbol. La majoria dels adolescents entrevistats tenen una gran afecció al futbol, i el practiquen al pati de l'institut o en un equip. És a dir, el futbol determina en bona mesura la dinàmica que es produeix a l'hora de l'esbarjo. Com ha mostrat Bonal (1997), la disposició de l'alumnat en relació amb la pista de futbol al pati crea un centre i una periferia molt marcats: al centre se situen els nois, i a 
la periferia, les noies, amb una regularitat impressionant. Els nois s'imposen als més petits i a les noies; mentre les noies es reserven els racons del pati per conversar.

Aquells nois als quals no agradi jugar a futbol, per tant, quedaran relegats a la "periferia» de l'activitat central, al marge del temps i l'espai que els altres nois dediquen a jugar-hi. La preeminència del futbol també determina la relació amb les noies. Com que les noies no hi participen - és cert que ho fan cada cop més, però bàsicament com a espectadores i d'una manera menys generalitzada - mentre s'està jugant no hi ha interacció directa: els nois juguen entre ells i les noies fan altres coses. Com a molt, les noies «miren» com juguen els nois:

RaÚL: Sí, en el patio estamos todo el día jugando a fútbol.

E: Jugando a fútbol.

RAÚl: Y ahí sí que se liga.

E: ¿¿Se liga?

RAÚL: Sí. Las chicas van y están ahí mirando.

$\mathrm{E}:$ ¿Y cómo es, que te dicen algo o al final?

RAÚL: Que [...], con las tonterías esas que empiezan.

$\mathrm{E}:$ ¿Las chavalas?

RAÚL: Te miran o ¿cómo se llama ese, el portero, cómo se llama alguien? Te miran jugando a fútbol.

És per això que podem dir que el futbol contribueix també de manera clara a definir l'espai propi d'allò masculí, en contraposició a l'espai femení, i no ha d'estranyar que durant l'adolescència, quan les relacions amb l'altre gènere guanyen preeminència, es redueixi molt el temps dedicat al futbol.

Molts entrevistats identifiquen el fet d'estar parlant amb noies i el d'estar jugant a futbol com les dues alternatives més comunes a l'hora del pati a l'institut. És a dir que també parlen amb elles. Però quan ho fan, sovint es posa en «escena» tota una altra estratègia de representació del rol masculí. Per exemple amb la tàctica de mostar-se molt agosarat («hay que ser lanzado con las chavalas»), del que diuen "vacilar», o de mostrar-se més assenyat, més caut.

SERGI: Sí, canvia bastant. Perquè, clar, quan estàs amb nois, és clar, es diuen moltes grosseries, això des del punt de vista de les noies i parlen molt obertament. De vegades estàs amb noies i clar, no pots parlar obertament, perquè no és facil, i a més, clar, tu penses: «Si jo parlés com amb els meus amics, no m’acceptarien». Amb els amics és normal que parlis d'alguns temes grossers i potser a elles no els agrada.

Aquests dos mons segregats tenen pautes de socialització i tipus de relacions socials diferents, i per tant l'agressivitat es manifesta de maneres diferents. Fixem-nos, per exemple, en l'agressivitat entre nois tal com és reflectida a les entrevistes que vam fer en un centre de secundària predominantment obrer. Entre els nois - especialment els de classe obrera- s'estableix un tipus de relacions físiques que, sense poder-se catalogar clarament d'agressions, estan 
al límit d'aquestes. És el «joc de barallar-se». Els entrevistats reconeixen que les empentes i els petits cops formen part d'un joc habitual entre nois: "Nos empujamos, sobretodo en gimnasia, de picardía, para ver lo que dice». És en aquestes circumstàncies quan l'agressivitat física es revela com un joc masculí.

Segons Parkhurst i Hopmeyer (1998: 128), darrere d'aquest joc (para ver lo que dice) els adolescents estan comprovant i establint dominacions d'una manera socialment acceptable, a la vegada que posen a prova l'habilitat dels altres per mantenir la posició i resistir la dominació. És a dir, que quan aquest noi es diverteix a la classe de gimnàstica, a la vegada està situant-se i situant els altres, de manera que es comprova qui no suporta les empentes, qui es mostra covard, qui es mostra perillós, etc. Davant d'aquest joc, i també de l'enfrontament més seriós, cada jove ha de definir la seva posició, tot i que la majoria no té consciència de la part seriosa que comporta, sinó que es veu com una manera normal de relacionar-se.

JOSE: Que si eso lo hacemos, a lo mejor, una vez en clase para ver lo que pasa, pero siempre de cachondeo. Le decimos cosas. Después, como sabe que es cachondeo, ya pasa de todo.

D'altres, en canvi, es neguen a establir una frontera clara entre aquestes bromes i les empentes i les baralles, perquè creuen que aquest joc «siempre acaba mal», i per tant hi estan totalment en contra. I és que el fet que el joc de barallar-se sigui masculí no vol dir que tots els nois siguin físicament agressius per definició. En realitat, només a una minoria dels nois els agrada la violència física i barallar-se, tot i que tots els entrevistats reconeixen que existeix un risc quotidià que la baralla es produeixi. No és un risc molt alt, però sí que és un risc que tenen present. En l'espai juvenil, un dels envits que defineixen la manera de ser masculí és el d'intervenir o no en baralles, l'actitud davant el risc que existeix en les relacions amb els altres d'arribar a barallar-se. Aquest risc és més accentuat en determinats ambients, determinats barris i determinades esferes. Quan se surt de nit a bars i discoteques, per exemple, l'alcohol i la situació fan que la possibilitat de baralla estigui més present.

L'institut és un d'aquests ambients en el qual existeix la possibilitat de barallar-se, ja que en les relacions entre adolescents el joc de dominació social que s'amaga darrere la burla, l'insult i les provocacions forma part de la vida diària. En un institut s'hi barregen joves diferents que desenvolupen afectes i animadversions, i que lluiten per assolir i mantenir un grau satisfactori de dominació social, d'autoestima i de reputació. La majoria d'adolescents procuren evitar tant com poden l'agressió física, però, tot i així, hi ha dos elements que fan que aquesta sigui una possibilitat real. D'una banda, el risc que el joc de bromes, burles, insults i petites provocacions vagi a més sense que cap dels implicats ho pugui evitar, i, d'altra banda, el fet que a una minoria de joves sí que els agrada o busca contínuament l'agressivitat física per imposar-se als altres.

L'agressivitat física, a més, no només es dóna com a resultat de la competència més o menys individual per a la dominació social, sinó que també és 
producte de les relacions conflictives que s'estableixen entre grups (entre grups classe, entre grups d'amics, entre centres, entre joves d'estils juvenils diferents, etc.). Aquestes animadversions poden basar-se en habitus diferents reforçats per currículums diferents. Els entrevistats, per exemple, parlaven de «els de metall, que són més violents», o "els d'administratiu, que són més calmats».

La majoria dels nois que vam entrevistar deien que algun cop o altre havien participat en alguna baralla. Quasi tots, malgrat això, deien que no els agradava gens barallar-se i alguns fins i tot deien que ho odiaven. Tots identificaven l'existència de la figura del chulillo, de l'adolescent que utilitza l'amenaça i l'agressió física per prendre posicions a la classe, per dominar els altres, o per formar un grup d'adeptes que «el respecten» per la seva capacitat d'imposarse als altres. Els chulillos són una minoria molt petita, però tenen un pes molt important a l'hora de definir el tipus de relacions socials que s'estableixen a l'institut, ja que, per pocs que siguin, són capaços de fer que la violència es respiri en l'ambient.

Es pot ser totalment contrari a les baralles però barallar-se, perquè hi ha moments en els quals molts joves consideren que no fer-ho implica posar-se en evidència. Les baralles són, normalment, un cas extrem. Els enfrontaments se solucionen habitualment en el que Paul Willis (1998) anomena «joc dels apaivagaments», que consisteix en complicats diàlegs i negociacions, verbals o no, en els quals es porta a terme una lluita simbòlica. En aquesta lluita simbòlica, totes dues parts procuren sortir-se'n amb la dignitat intacta però sense barallar-se.

L'honor i la reputació són molt importants (no ser un gallina) i per això cal aprendre a sortir d'aquestes situacions de manera que la dignitat no quedi ferida. D'això depèn en part el grau de dominació social. Si algú no sap fer front a les amenaces, pot convertir-se en l'objectiu de totes les bromes. I al revés, si algú mostra que mai es deixa trepitjar, ningú s'atrevirà a enfrontars'hi. L'actuació de cada jove davant el joc d'apaivagaments i intimidacions i les baralles és important, per tant, per al seu posicionament davant dels altres i per a la negociació de la seva identitat masculina.

Així, per exemple, un dels adolescents entrevistats, a qui no li agrada barallarse («Siempre que no haya motivo fuerte, mejor no pelear»), es defineix com dels que aguanta la posició, dels que no deixen que un afront els faci semblar menys forts davant dels altres. "Que no te toquen los huevos» és una expressió que significa una amenaça per a tot aquell que superi els límits que imposa mantenir la pròpia dignitat. En canvi, un altre dels adolescents diu que «soy de esos que venga, digo adiós y me voy. Pero alguna vez me he quedado yo, y les planto cara. ¡No siempre vas a ir yéndote!». Un altre explica que com que ell és incapaç de barallar-se físicament, ha après a fer mal amb les paraules («Yo les pico hablando»). Al costat d'aquests, hi ha els que mai es barallen, i alguns - molt pocs - que tenen assumida la baralla com una part habitual de la seva existència: els chulillos.

Tots defineixen la seva masculinitat els uns en relació amb els altres. Els chulillos defineixen la seva masculinitat agressiva en relació amb els altres que no 
saben resistir les seves agressions, i els joves més menys agressius defineixen la seva masculinitat no hegemònica en relació amb els joves «més durs». Ja hem dit més amunt que segons la classe social la relació entre masculinitat i agressivitat física és diferent. En un ambient menys agressiu, les masculinitats prenen altres formes, ja que, per començar, no cal defensar-se de cap agressió física, i per tant aquest no és un element rellevant per a la masculinitat.

En canvi, en general, la feminitat es relaciona amb els tipus d'agressivitat més indirectes. En general, en els grups de discussió les noies distingeixen entre la seva manera de «fer-se mal», més relacionada amb els sentiments, i la manera de barallar-se dels nois, més física. Però aquestes diferències no estan al marge de la classe social. Ja hem dit que l'agressivitat física és molt possible que sigui acceptada per les noies de classe obrera. De fet, quan a les noies se'ls planteja la qüestió de la diferència entre nois i noies, facilment sorgeix la idea d'aquesta distinció entre agressivitat indirecta i agressivitat directa (física o verbal). Mentre que en algun grup de discussió ${ }^{5}$ en què no es planteja directament aquesta qüestió, la distinció no és tan clara.

Les noies d'un institut de la periferia d'una ciutat gran, amb alumnes d'origen obrer i amb una certa marginalitat, ens van explicar que les noies també es peguen, però entre elles. La manera que tenen de relacionar-se amb l'agressivitat física no és gaire diferent de la dels nois. Comencen amb insults, males paraules, en broma... I de vegades acaben barallant-se físicament.

JÉSICA: Yo, a mi me gusta chinar a una persona, que se enfade conmigo, pero luego hacemos las paces. Ya está.

[riuen]

E: ¿Y os peleáis de verdad, o...?

TOTES: No.

JÉSICA: No, en broma.

PATRICIA: Hombre, a mí a veces me ha..., se me ha ido la mano.. Por una tontería. Por eso de que te picas y luego al final...

JÉSICA: A mí siempre me pasa eso. Empiezo de cachondeo y acabo...

Aquestes noies també critiquen els seus companys o companyes que delaten les agressions: "A mí lo que me da rabia de las niñas de mi clase que vayan [...] a los profesores y...». Això no vol dir que no critiquin l'actitud dels nois amb elles. Algunes són molt clares distingint la seva manera de ser i la dels nois. Encara que acceptin els seus companys tal com són, també són molt conscients que el masclisme les perjudica, les relega a un segon pla, per exemple quan per fer-se els durs amb els amics fan veure que la nòvia no té cap importància. Les noies, doncs, coneixen molt bé les regles de joc de la masculinitat dels nois amb qui es relacionen, $\mathrm{i}$ les accepten com a tals, com a part del joc, però

5. Aquesta diferència la vam poder comprovar entre els tres grups de discussió realitzats als instituts de Vilafranca, Castelldefels i Tomelloso, i quatre grups de discussió realitzats a Sabadell. Aquests últims estaven diferenciats per la procedència social de classe. 
no les comparteixen del tot; sempre hi mantenen una certa distància, ni que sigui perquè es troben una mica fora, en una posició de dominació.

Això no vol dir que no reaccionin davant d'aquesta dominació masculina. Però mentre les noies de l'institut de classe obrera responen reivindicant la seva participació en l'agressivitat física («Si le tengo que dar una torta se la doy»), les noies dels instituts de classe mitjana responen rebutjant la violència física. Com ja passava en el cas dels nois i la masculinitat, les noies no responen a un únic model de feminitat, sinó que opten entre diferents possibilitats: la noia molt femenina, la masculina, la marimacho, la moderna i alliberada, etc. Hi ha noies amb una actitud agressiva, i d'altres que rebutgen aquesta agressivitat, com es pot veure en aquest diàleg d'un grup de discussió amb noies d'un institut públic de classes mitjana i obrera:

EvA: Hi ha gent que la mires i diu: "Qué estás mirando, a que te pego! a que llamo a mis amigas!». Això ja és ganes de bulla.

JUDIT: Sí.

AIDA: Sí, són tribus urbanes.

Aquestes noies que rebutgen recórrer a les agressions físiques són les que marquen més les diferències entre nois i noies. Són les que tenen més assumit el discurs recurrent segons el qual els dos sexes tracten de manera diferent els seus "piques» (problemes, diferències, enganxades). També els nois que es distancien més de l'agressivitat física són els que fan referència a aquesta característica de les noies. Amb paraules d'uns entrevistats (nois), les noies són més subtils a l'hora de "picar-se» amb algú, però també més trä̈cioneres:

JORDI: Jo diria que sí, jo què sé, potser un tio amb un altre tio, potser es traguen o s'insulten un dia i ja són amics. I les ties es piquen i ja... Però és que potser es fan molt amiguetes de «ha, ha», i se'n van $i$ ja...

TOMÀs: És això, hi ha molta falsedat. De vegades van allà tope d'amigues i quan se'n van..., comencen a criticar-les i...

Això és confirmat també per diverses noies, que deixen clar que elles també exclouen altres noies, però ho fan en les seves relacions d'amistat (que normalment vol dir d'intimitat): «No porque las mujeres somos más rencorosas. Las mujeres a lo mejor... Yo a lo mejor me puedo pelear con ella y en vez de pegarle un bofetón decir "ya verás la putada que te voy a hacer"...». Els adolescents interpreten això dient que les noies són més madures, més llestes. Però no ho diuen com un elogi, sinó com un retret, com una crítica. També és una manera de dir que les noies són menys nobles que els nois, que no participen de les regles del joc masculí de l'agressivitat. Així, malgrat que els nois i les noies en posicions més altes o intermèdies en l'estructura social rebutgen l'agressivitat física i utilitzen tipus més indirectes d'agressivitat, els nois continuen veient en les noies comportaments diferents dels seus. Segurament, perquè malgrat que els nois puguin utilitzar també tipus d'agressivitat indirecta, no ho fan de la mateixa manera. Igual com no es comporten de la mateixa 
manera, segons diuen, a l'hora de formar els grups d'amics o d'amigues, d'anar junts o juntes, d'explicar-se intimitats, etc.

D’altra banda, si bé no es pot dir que les noies siguin menys agressives, sí que hem pogut comprovar en el nostre estudi que la seva capacitat per imposar-se als altres és més limitada. En primer lloc, perquè queda circumscrita a les relacions amb persones del mateix sexe. En segon lloc, perquè la dominació masculina s'expressa també en la capacitat d'agredir i no ser agredit pel sexe femení. En aquest sentit, és molt interessant l'estudi etnogràfic sobre les New Wave Girls que féu Shane Blackman (1995). En aquest estudi es va veure com un grup de noies d'un institut havien aconseguit evitar les agressions verbals dels nois gràcies a un estil agressiu en el vestir $i$, sobretot, a la seva manera de comportar-se: quan els nois les increpaven, s'hi tornaven parlant de sexe, de la regla i de compreses; estaven molt unides i es tocaven molt, la qual cosa feia que la gent els digués lesbianes, tot i que totes elles tenien xicot; feien festes entre elles, i feien córrer rumors sobre les que havien fet, amb la qual cosa es creava un mite sobre el grup a l'escola.

\section{Control}

Hem dit que l'agressivitat és un element intrínsec en les relacions socials entre els adolescents. Però a la vegada hem vist com segons el gènere i la classe social, així com segons el tipus de masculinitat, s'exerceix o es negocia de maneres diferents. També hem vist fa un moment com diversos nois asseguren que l'agressivitat indirecta és més «madura», més «intel-ligent». A continuació desenvoluparem aquesta idea a partir de la idea del «control».

En primer lloc, cal desmuntar la percepció de l'agressivitat, i especialment de l'agressivitat física, com a "descontrol». Ja hem dit com fins i tot en les baralles, quan aparentment es perd el cap, els individus mantenen un control que els fa seguir un codi ètic culturalment determinat. També hem parlat de les elaborades negociacions simbòliques implícites en el joc de l'agressivitat, i de les fines línies que separen el joc de l'agressió. Per a alguns joves, a més, l'agressió física i les baralles tenen un important component lúdic, ja que s'experimenten com a font de diversió, d'aventura. És mentida, per tant, que en les relacions agressives no hi hagi control. Sí que podem afirmar, en canvi, que aquest control és invisible als ulls dels adults, o dels grups que rebutgen les baralles. El rebuig a les agressions implica també el rebuig a la lògica que les argumenta.

En segon lloc, cal emfasitzar que per comprendre l'agressivitat s'ha d'anar més enllà de la creença segons la qual aquesta és producte del descontrol patològic d'uns quants individus. Hem insistit durant tot l'article a veure l'element quotidià de l'agressivitat, i de fet podríem parlar d'un control grupal dels individus per tal que aquests siguin agressius. Estem fent referència sobretot al joc de l'agressivitat que hem dit que és habitual en certs ambients. Hem vist com respon a una expectativa social, és a dir, que els nois creuen que és el que s'espera d'ells, i que per això l'escenifiquen. No només per man- 
tenir un cert grau de dominació social, sinó també per mostrar-se atractius davant de les noies, per exemple. Aquest joc de l'agressivitat no ha d'anar lligat necessàriament a una agressivitat física tal com l'hem definit, però és evident que implica un tipus de relacions socials en les quals l'agressivitat hi és molt més present. Els nois adolescents acostumen a relaxar aquesta escenificació a partir dels setze anys. Alguns entrevistats van explicar-nos com ara estaven en un procés de transició - havien «madurat»— i que s'havien «adonat» que això era una estupidesa, ja que per relacionar-se amb les noies calia seguir altres estratègies.

Ara bé, dit això - l'agressivitat física no és una manca de control i sovint és producte d'un control del grup_-, sí que podem establir que l'agressivitat física implica un menor grau de control en el sentit que formula Norbert Elias (1989) en relació amb el que anomena "procés de civilització». Segons Elias, aquest procés de civilització consisteix en la progressiva instauració de controls entre els impulsos i la conducta, que han permès la configuració de l'homo clausus occidental, separat dels altres individus pels murs del seu cos i amb un fort control de la seva conducta: això fa que el contacte entre els cossos estigui cada cop més mal vist, fins al punt que el contacte físic entre cossos, o fins i tot entre objectes que han tocat altres, s'evita tant com es pot. No utilitzem coberts que han utilitzat altres si no han estat rentats, no dormim amb estranys a la mateixa habitació, arraconem les excrecions del cos a un espai reservat, etc.

Aquest procés de civilització va directament lligat al procés de modernització i a la producció industrial. Sense aquest autocontrol seria impossible coordinar la complexa divisió del treball, que requereix un ordre i una fiabilitat impensables fa uns segles. Cal que la gent treballi i compleixi el que s'espera d'ells fins i tot quan els ha deixat la parella, quan estan emprenyades, quan s'estan enamorant o quan tenen ganes d'anar al bar. I cal fer-ho amb precisió matemàtica, perquè cadascú de nosaltres és una peça en l'engranatge de la complexa divisió laboral. Cal saber controlar i posposar els impulsos, i això no és gens facil. L'impuls agressiu n'és un.

Així que per arribar a les societats tan complexes i poblades actuals ha calgut controlar i coordinar el temps i les nostres accions. I ha calgut controlar la violència, que com hem dit al començament de l'article, a finals de l'edat mitjana es va començar a considerar un «problema social». D'altra manera, com s'explica que puguem conviure amb cert ordre milions d'individus en un espai tan petit com les metròpolis actuals? Allò que és sorprenent, en certa manera, no és tant que hi hagi violència, sinó que n'hi hagi tan poca! Això seria impensable sense el monopoli de la violència legítima que exerceix l'Estat modern, i sense el control del cos inculcat per mitjans com ara l'escola de masses i el moviment higienista.

Aquest procés de civilització al qual fa referència Elias, va començar a les corts dels estats absolutistes. És a dir, a la part més elevada de la piràmide social. Va ser aleshores quan es va assimilar el refinament en la conducta a l'alta societat. I de les corts es va anar estenent progressivament a la resta de classes socials 
fins afectar el conjunt de la societat. Encara ara com més amunt en l'estructura social s'està, m'és refinat s'és i més autocontrol cal mostrar en el llenguatge, el moviment del cos, en la manera de menjar, etc. També en l'agressivitat física, que cal sublimar en altres tipus d'agressivitat més elaborats.

Els individus amb més autocontrol i refinament són, per tant, els que ocupen les posicions dominants en l'estructura social (no és com a l'edat mitjana, quan les classes dominants - els nobles - donaven molta importància a la capacitat de lluita i a les proeses físiques, i ben poca a les bones maneres). És en aquest sentit que podem dir que l'agressivitat física si que constitueix una manca de control.

A la vegada, paradoxalment, si ens fixem amb els gèneres, veurem que són les dones les més refinades i les que més autocontrol mostren en els tipus de conducta. Ens tornem a trobar, per tant, la paradoxa a la qual havíem fet referència parlant de l'agressivitat: les noies en general i els nois de classes mitjanes i altes mostren una conducta similar en tant que tendeixen a manifestar tipus indirectes d'agressivitat — que requereixen més autocontrol i sofisticació-, mentre que les classes obreres i els homes en general tendeixen a agredir més físicament i verbalment.

Acabem de dir més amunt que el procés de civilització és inseparable del procés de modernització i dels estats moderns. De la mateixa manera, podem analitzar com els diferents tipus d'agressivitat es relacionen i encaixen en les societats modernes industrials: per tenir una carrera ascendent, cal un autocontrol considerable per renunciar a la satisfacció present en mires a una de futura (una bona posició al mercat laboral) i per encaixar en les institucions que canalitzen aquest ascens (l'escola, el lloc de treball, etc.). Per fer aquest sacrifici cal un control dels impulsos i la satisfacció en el present: en lloc de sortir, mirar la televisió o escoltar música, sovint cal estudiar i fer un esforç que no és plaent. És molt interessant veure les diferents maneres com el resolen els adolescents: és el gran dilema entre divertir-se o estudiar.

Les entrevistes contradiuen completament la idea segons la qual els joves no estan interessats en els estudis. Pels nois entrevistats els estudis ni són inútils ni estan deslligats del fet de trobar feina. Al contrari del que podríem suposar, els estudis tenen un valor molt accentuat com a mecanisme d'accés al mercat de treball entre els adolescents i les adolescents. És veritat, malgrat això, que en les entrevistes i grups de discussió hem pogut veure que les noies tenen una concepció molt més meritocràtica de l'educació i la transició al món laboral que no pas els nois. Elles tenen més clar que cal lluitar per poder realitzar les seves aspiracions professionals, mentre que els nois expliciten menys aquest tipus de discurs i emfasitzen més les dificultats actuals per trobar feina.

MARÍA: Nosotras queremos tener nuestro orgullo y decir: «mira, estoy aquí y gano tanto dinero porqué en mi vida he trabajado y me lo he currado»; y los hombres no, los hombres van ya a ganar dinero, tener su familia, no piensan en el futuro. 
La majoria d'entrevistats masculins havia repetit algun curs, a primària o a secundària (entre el conjunt d'estudiants de gènere masculí el fracàs escolar és més gran que entre les noies). Però cap no va manifestar una actitud antiescola, sinó al contrari. Tots els nois entrevistats - fins i tot aquells que sembla que poden deixar els estudis abans d'acabar el que estan fent-creuen en la formació com un element importantíssim per facilitar la incorporació al món del treball, i fins i tot per madurar com a persones. Per tant, pel que fa al valor de l'educació, no hem percebut en el discurs d'aquests adolescents una desvalorització d'aquesta mena.

Ara bé, estudiar és una obligació de cara al futur, amenaçador però llunyà, mentre que en el present hi ha sempre la possibilitat seductora de divertir-se i passar-ho bé. El dilema està servit: quant de temps han de dedicar a les relacions amb els amics i a la diversió, d'una banda, i quant de temps han de dedicar a la vida acadèmica, de l'altra. Això és especialment manifest entre els adolescents que passen bona part del seu temps lliure al carrer i que es mouen en un context -família, amics, etc. - molt distant de la cultura acadèmica. És sobretot en aquests casos que els estudis es viuen de manera més radical com una obligació en tensió amb la diversió del «temps lliure». De vegades, en aquesta lluita per mantenir un equilibri entre divertir-se i estudiar, alguns alumnes perden el control $i$ es troben sense adonar-se que han repetit un curs.

FELIPE: Depende, porque en el tiempo libre, también hay veces que tienes que estudiar y..., una cosa es estudiar y otra cosa es divertirte. Son dos términos.

$[\ldots]$

E: ¿Pero el año pasado pasabas más, no?

FELIPE: El año pasado sí. Pasaba de todo.

E: Era todo tiempo libre.

FELIPE: Todo tiempo libre...

E: ¿Sí?

FELIPE: Todo era hora del patio.

E: ¿Y ahora has encontrado un equilibrio?

FELIPE: Claro, este año, como te centras más, sabes que si no, repites, pues te van a echar, te vas centrando, lo intentas.

Per això cal un control, que es pot exercir en grau diferents. En un extrem hi ha el «descontrol» total, que és el d'aquells estudiants que no estudien gens, els passotes que acaben deixant els estudis. A l'altre extrem, els que pràcticament només estudien, que són el que la resta de joves anomena despectivament empollons. Aquesta divisió és molt important, fins al punt que un entrevistat, quan li vam preguntar com classificaria els joves de la seva edat, va contestar així: "Trobaríem dos grups que serien els que a la nostra edat estan fent estudis i per l'altra els que no estan estudiant, els que han deixat els estudis». Com ens va dir un altre entrevistat, aquells que poden combinar el fet de no estudiar pràcticament gens amb els bons resultats acadèmics són, d'alguna manera, uns herois. 
Ara bé, tot i que aquests graus de control els trobem arreu, com passava en el cas de l'agressivitat, segons l'institut, el gènere, la classe social, la família o l'individu, el control pren formes diferents. Com més amunt en l'estructura social, més rígid és el control que s'espera com a normal. Això es fa explícit quan parlem amb alumnes que han passat d'instituts privats de classe mitjana a instituts públics amb majoria d'alumnat de classe treballadora, o al revés. Un afirma que "potser l'ambient aquí [escola privada] és una mica més selecte, i allà [institut públic] són una mica més esverats, i no paren temps pels estudis». Una altra comenta que quan va passar de l'escola privada de classe mitjana a l'institut públic va notar com en aquest es treballava molt menys, i que la gent estava molt més al carrer.

De la mateixa manera que el control sobre els impulsos agressius canvia segons la posició en l'estructura social i la composició social del centre, el control sobre els estudis considerat «normal» — i habitualment la quantitat de feina exigida - és diferent segons el centre i la classe social. D'altra banda, a més, també varien les formes que pren el control. Podem distingir un control extern dels pares, professors i companys, d'una banda, i un altre internalitzat dels mateixos adolescents. En altres paraules, que el control s'assoleix de maneres diverses i amb una gran influència de l'entorn i les circumstàncies. Fins i tot quan el control és intern - per sentiment d'obligació, culpa o responsabilitat- això tendeix a ser conseqüència no només d'un "caràcter» determinat, sinó també d'un tipus de socialització determinada ${ }^{6}$. En aquest sentit, els estudis de Bernstein (1988-1989) ens mostren com el control sobre la pròpia conducta dels joves de classe obrera és diferent del control dels joves de classe mitjana. En el primer cas, el control s'exerceix de manera col-lectiva i externa, en el segon cas, de manera individual $\mathrm{i}$ interna.

En les entrevistes vam poder comprovar la influència de la família en la importància que els mateixos nois atribueixen al rendiment acadèmic. Els pares també poden ser importants a l'hora d' «ajudar» a posposar el desig de «divertir-se» i, en alguns casos, fins i tot a desfer l'oposició radical entre «divertir-se» i «estudiar». La família és important en l'educació per l'autocontrol, sobretot en el cas d'alumnes amb dificultats. A la vegada, però, la pressió familiar també pot ser motiu d'estrès i de baixa autoestima. La família també té molta influència en la definició de l'orientació curricular i les expectatives d'aquests adolescents, tant a causa de la cultura que transmet la socialització familiar, com dels consells sobre quin tipus d'estudis han d'escollir.

6. El control, a més, és important no només en els estudis, sinó també en la majoria d'àmbits de la vida dels adolescents. Un és el de la droga. Aquesta citació d'una noia és especialment significativa: «No, es que..., no te das cuenta, no te das cuenta, te crees que puedes..., que puedes controlarlo, y llega un momento que..., y como tampoco quieres porque te es tan guay..., pues..., pero no puedes, no puedes, te da algo. Una amiga mía le dijo a su padre que se drogaba para que no la dejaran salir, y al final le tuvo que decir que era mentira para que la dejara salir otra vez.» 
RAÚl: [Mi madre] dijo que me convenía [hacer administrativo]. Yo tenía el graduado. Me iba a BUP, pero dijo mi madre que no, que administrativo.

E: ¿Tú preferías hacer BUP?

RAúL: Yo sí.

$\mathrm{E}:$ ¿Y por qué te dijo que no?

RAÚL: Dijo que me convenía más administrativo, porque el BUP lo catean muchos.

E: ¿Que ibas a catear? ¿Y te iban bien los estudios o te costaban?

RAÚl: Hombre, costaba un poco, pero, es que yo, no se me quedan mucho las cosas, tengo que estudiar mucho, mucho, pero ahora me va bien.

La cultura acadèmica va lligada al procés de civilització. De fet, les escoles han estat sempre un instrument fonamental en aquest procés, ja que han imposat la disciplina i l'autocontrol, la higiene i el refinament. Els adolescents amb una orientació més acadèmica tendeixen a convertir l'agressivitat física i verbal en indirecta. Especialment els nois de classe mitjana i les noies en general. El control de l'agressivitat física i verbal i la seva substitució per aquesta agressivitat indirecta és la que és més acceptada en les societats modernes.

Això planteja qüestions interessants. Perquè l'agressivitat indirecta sigui efectivament la que ordena les jerarquies, cal que l'agressivitat física — i en part també la verbal- estiguin «controlades». És a dir, cal que hi hagi ordre, imposat per pares, professors, policia, exèrcit, etc. Si no hi ha aquesta repressió de l'agressivitat física, aleshores l'agressivitat indirecta perd gran part del seu poder, ja que en darrera instància serà la física la que s’imposarà a còpia de garrotades. En contextos on l'agressivitat física es respira en l'ambient, mantenir la posició i no ser un gallina és fonamental; en ambients de classe mitjana, davant una provocació no és un deshonor tan gran avisar l'autoritat. Són dues maneres d'encarar les relacions socials que tendeixen a anar lligades a dues maneres de fer en la vida adulta: una de perfectament habituada a utilitzar els recursos d'enfrontament civilitzat (burocràcies, meritocràcia, sistema legal, etc.) i una altra amb dificultats per utilitzar aquests recursos.

Aquelles persones i sectors socials amb un habitus on l'agressivitat directa és més habitual, per tant, practiquen uns tipus de control que no s'ajusten a la forma civilitzada (entesa no com un judici valoratiu, sinó a partir d'una realitat històrica, i per tant socialment construïda) de relacions socials. I això els situa en desavantatge - ja que tenen menys eines - per adaptar-se als creixents riscs $\mathrm{i}$ incerteses en les societats industrials (atur, precarietat laboral, etc.). O com va observar Paul Willis (1981) en el cas dels nois antiescola que va estudiar, les seves produccions culturals, sovint extremament lúcides, els porten a reproduir una posició dominada en l'estructura social. L'agressivitat física pot ser, en determinades circumstàncies límit, una eina per a l'emancipació social, però sovint és exactament el contrari: un element més d'un habitus que participa activament en la reproducció de la posició dominada d'aquells que ja estan en desavantatge. 


\section{Conclusions}

Hem analitzat l'agressivitat a les escoles en relació amb l'experiència viscuda pels mateixos adolescents, d'una banda, i amb la seva estructuració social, de l'altra. Això ens ha permès comprendre el seu sentit en les biografies individuals dels joves, en la seva vida quotidiana, i la manera com va lligada a processos històrics i a la mateixa estructura social.

Parlar de l'agressivitat a les escoles és parlar de relacions de poder: entre els mateixos alumnes, entre classes socials, entre l'Estat i els ciutadans, etc. Això és el que hem disseccionat en aquest article: la dinàmica social que s'amaga darrere del problema de l'agressivitat als instituts. Això permet entendre com no estem tractant només amb alumnes conflictius, sinó també amb tipus d'organització social i amb tipus de relacions socials i culturals molt més àmplies i arrelades, lligades als processos històrics de modernització i civilització, a les relacions de dominació en l'estructura social i les relacions desiguals entre gèneres, així com les relacions personals desiguals i la competència entre els propis alumnes.

Això ens ajuda a entendre que pràcticament totes les relacions socials estan mediatitzades per l'agressivitat i a copsar que l'agressivitat física és només un dels aspectes que adquireix. També ens ajuda a copsar que l'agressivitat física és part inherent de la vida quotidiana de molts adolescents, sobretot dels nois i noies que ocupen posicions més baixes en la jerarquia social.

Aquesta anàlisi dels tipus d'agressivitat en l'adolescència és pertinent perquè ens trobem en un moment de canvi cultural molt important. En primer lloc, la comprehensivitat a les escoles presenta problemes nous. En segon lloc, som en un moment de canvi en les condicions socials que afecten homes i dones. Molts treballs manuals, tradicionalment masculins, estan desapareixent. L'augment de la població activa femenina implica, necessàriament, una redefinició dels rols en l'àmbit domèstic. En general, els tipus de relació social entre homes i dones estan canviant. I, malgrat tot, les relacions entre nois i noies adolescents reprodueixen formes sexistes de manera força desacomplexada. I, en tercer lloc, els tipus d'autoritat s'estan transformant, tant entre homes i dones com entre generacions i grups d'edat. L'autoritat per l'autoritat està perdent pes, perquè la violència física exercida per pares, marits i professors s'ha convertit en il.legal, i això implica que cal desenvolupar nous sistemes de relacions socials molt més elaborats. A la vegada, les cultures juvenils fan que els referents culturals dels joves estiguin cada cop més deslligats dels dels adults, la qual cosa dificulta aquesta necessitat de diàleg imposada per la il.legalitat de les formes autoritàries de relacions socials.

\section{Implicacions}

Per afrontar aquests canvis socials que es produeixen, així com els problemes nous que sorgeixen, pot ser molt útil desemmascarar les regles socials que 
regeixen les nostres relacions, i fer-les conscients als ulls dels actors socials. Aquesta aproximació no aporta cap solució ni recepta al "problema» social de l'agressivitat, però sí que aposta per una comprensió dels fenòmens que no deixa d'enriquir-nos. L'agressivitat és un fenomen que hem d'entendre en la seva «normalitat», i això vol dir desproblematitzar-lo en un cert sentit, per poder-hi descobrir les veritables desigualtats socials que produeix. Desemmascarar les relacions socials que hi ha en els tipus d'agressivitat entre adolescents, no deixar que sigui un aspecte estrany (extraordinari) segurament és més útil al professorat dels instituts que no pas la seva conversió en un "problema». Aquest tipus d'aproximació, a més, també ens pot curar de temptacions paternalistes, i obligar-nos a afrontar l'educació amb més (sempre difícil) diàleg cultural entre professorat $\mathrm{i}$ adolescents.

Igualment, en les relacions de gènere la manera d'abordar els tipus d'agressivitat és una qüestió molt important. Hem vist com les relacions són sexistes en la mesura que tant els nois com les noies accepten una determinada definició dels seus rols. El problema (percebut) més immediat per a uns i altres, però, no és el sexisme, la jerarquia o la dominació del gènere masculí, sinó la segregació en dos mons separats d'uns i altres. Per a molts nois, encarar les relacions amb les noies implica deixar de banda el seu grup i enfrontar-se a un control individual de la situació. També implica obrir-se al diàleg, a la negociació.

Actualment hi ha un discurs socialment dominant sobre la necessitat del diàleg, de la negociació. Aquest discurs ha tingut la seva expressió pedagògica en l'educació amb valors, que preconitza la necessitat d'educar per a la pau, la solidaritat, la col-laboració. Malgrat aquest discurs, i les condicions més igualitàries que han sorgit a l'escola entre professorat i alumnat, en general es troben a faltar mecanismes que facin possible aquest diàleg. Pensem que això no és aliè al fet que el discurs educatiu dominant rebutja de ple l'agressivitat, però des del desconeixement. El que no es té en compte en general és que la possibilitat d'una negociació implica tant el reconeixement de l'existència de tipus de poder, que s'expressen mitjançant la violència simbòlica o les agressions indirectes, com el mateix aprenentatge del diàleg com a mitjà de mediació dels conflictes.

En aquest sentit, els canvis socials actuals plantegen un nou escenari que requereix noves produccions culturals, és a dir, re-produccions dels antics models de relacions culturals entre individus, entre sexes, entre generacions i entre actors socials. I això implica nous conflictes i probablement noves maneres de dirimir-los. Interpretar els tipus d'agressivitat que es donen al nostre voltant, en les relacions socials quotidianes, ens pot ajudar a entendre quines desigualtats, quins conflictes, quins interessos s'hi expressen o s'hi amaguen. I també quins models de relació, i sobretot d'expressió dels conflictes, dels interessos, poden ser més igualitàries, és a dir, més democràtiques. 


\section{Annex}

Qüestionari sobre l'agressivitat que pateix l'alumnat

Sexe:

Curs:

1. Quantes vegades t'han agredit aquest mes?

2. Quin tipus de comportament agressiu has sofert?

Mai Una vegada Més d'una vegada

\begin{tabular}{|l|l|l|l|}
\hline Físic (cops, puntades de peu...) & & & \\
\hline Verbal (insults, malnoms...) & & & \\
\hline Escrit (paraulotes, grafits...) & & & \\
\hline Exclusions (no t'han deixat jugar...) & & & \\
\hline Burles (s'han rigut de tu...) & & & \\
\hline Sexuals (t'han tocat, amenaces...) & & & \\
\hline El teu material (amagat, fet malbé) & & & \\
\hline La teva roba (estirades...) & & & \\
\hline El teu menjar & & & \\
\hline Els teus diners & & & \\
\hline
\end{tabular}

3. On ha passat?

\begin{tabular}{l|l|l|l|} 
& \multicolumn{1}{c}{ Mai } & Una vegada & Més d'una vegada \\
\hline A classe & & & \\
\hline Al passadís & & & \\
\hline Al menjador & & & \\
\hline Als lavabos & & & \\
\hline Al carrer & & & \\
\hline A d'altres llocs & & & \\
\hline
\end{tabular}


4. Qui t'ha agredit?

Mai Una vegada Més d'una vegada

\begin{tabular}{|l|l|l|l|}
\hline Una noia del centre & & & \\
\hline Un noi del centre & & & \\
\hline Diversos nois del centre & & & \\
\hline Diverses noies del centre & & & \\
\hline Un grup de nois del teu curs & & & \\
\hline Un grup de noies del teu curs & & & \\
\hline Un grup de nois més grans & & & \\
\hline Un grup de noies més grans & & & \\
\hline
\end{tabular}

5. Enumera de l'1 al 6 les agressions que més et molesten

- Que et peguin.

- Que et donin puntades de peu o empentes.

- Que et tirin a terra.

- Que t'insultin.

- Que es posin amb la teva família.

- Que t'amenacin.

- Que t'amaguin les coses.

- Que et tractin de "tonta» o de «tonto».

- Que parlin malament de tu.

- Que no t'incloguin en el teu grup de companyes o companys de classe.

- Que es riguin de tu.

- Que t'ignorin.

- Altres agressions que no estiguin incloses en aquesta llista.

6. A qui ho expliques quan pateixes una agressió? 
7. Què t'agradaria fer?

Indiqueu la preferència $a m b$ una $x$

\begin{tabular}{l|l|}
\hline Que el/la professor/a els renyés & \\
\hline Que els teus amics o amigues li peguessin & \\
\hline Que no els deixessin tornar a l'institut & \\
\hline Que l'institut prengués mesures perquè & \\
aquestes situacions no tornessin a passar & \\
\hline
\end{tabular}

8. T'agradaria comentar alguna altra cosa sobre això?

\section{Bibliografia}

Askew, S.; Ross, C. (1989) [1988]. Boys Don't Cry: Boys and Sexism in Education. Milton Keynes: Open University Press.

BERNSTEIN, B. (1988-1989). Clases, códigos y control. 2 vol. Madrid: Akal.

Blackman, Sh.J. (1995). Youth, Positions and Oppositions: Style, Sexuality and Schooling. Aldershot: Avebury. [Univ. Lib.] 240.c.99.1483.

Bonal, X. (1997). Las actitudes del profesorado ante la coeducación. Propuestas de intervención. Barcelona: Graó.

Bourdieu, P. (1980). Questions de Sociologie. París: Éditions de Minuit.

BREHONY, K.J. (1998). "“I Used to Get Mad at My School”: Representations of Schooling in Rock and Pop Music». British Journal of Sociology of Education, 19 (1): 113-34.

Chapman, R.; Rutherford, J. (eds.) (1988). Male Order: Unwrapping Masculinity. Londres: Lawrence \& Wishart.

Connell, R. (1995). Maculinities. Cambridge: Polity Press.

Craig, S. (ed.) (1992). Men, Masculinity and the Media. Newbury Park: Sage.

Crouzet-Pavan, E. (1997). "A Flower of Evil: Young Men in Medieval Italy». A Giovanni, L.; Jean-Claude, S. (eds.). History of Young People in the West. Vol. 1. Ancient and Medieval Rites of Passage. Cambridge-Londres: Belknap Press de Harvard UP, p. 173-221. 
ELIAS, N. (1989). El proceso de la civilización. Investigaciones sociogenéticas y psicogenéticas. México D.F.: Fondo de Cultura Económica.

HANDRY, L. (1992). «Sport and Leisure. The not so Hidden Curriculum?». A Coleman, J.C.; Warren-Adamson, Ch. The Youth Policy in the 1990s. The Way Forward. Londres: Routledge.

Hayden, C.; MARTin, T. (1998). «"Safer Cities" and Exclusion from School». Journal of Youth Studies, 1 (3): 315-31.

HINES, N.J.; FRY, D.P. (1994). «Indirect modes of aggression among women of Buenos Aires, Argentina». Sex Roles. A Journal of Research, 30: 213-36.

Keltner, D.; Young, R.C.; Heerey, E.A.; Oemig, C.; Monarch, N.D. (1998). "Teasing in Hierarchical and Intimate Relations». Journal of Personality and Social Psychology, 75 (5): 1231-47.

MARTínEZ, R. (1998a). «El món dels joves: un recorregut per l'estudi de la cultura juvenil al món anglosaxó». Introducció a WILLIS, P. Cultura viva. Una recerca sobre les activitats culturals dels joves. Barcelona: Diputació de Barcelona.

- (1998b). Cultura juvenil i gènere. Una reflexió teòrica sobre l'espai social juvenil, l'emergència de noves formes culturals associades al consum i el gènere. Barcelona, manuscrit.

MaC an Ghaill, M. (1994). The Making of Men: Masculinities, Sexualities and Schooling. Buckingham: Open UP.

- (1996). "What about the boys?: schooling, class and crisis masculinity». The Sociological Review, 44 (3): 381-97.

McNamee, S. (1998). "The Home: Youth, Gender and Video Games: Power and Control in the Home». A SKelton, T.; Valentine, G. (eds.):\# 195-206.

Miles, S.; ClifF, D.; BurR, V. (1998). "Fitting In and Sticking Out': Consumption, Consumer Meanings and the Construction of Young People's Identities». Journal of Youth Studies, 1 (1): 81-96.

Owens, L.D.; MaCMullin, C.E. (1995). "Gender Differences in Aggression in Children and Adolescents in South Austrialian Schools». International Journal of Adolescence and Youth, 6 (1): 21-35.

PARKhURST, J.T. (1998). «Sociometric Popularity and Peer-Perceived Popularity: Two Distinct Dimensions of Peer Status». Journal of Early Adolescence, 18 (2): 125-44.

Pattman, R.; Frosh, S.; Phoenix, A. (1998). «Lads, Machos and Others: Developing "Boy-Centred" Research». Journal of Youth Studies, 1 (2): 125-42.

RigbY, K.; SLEE, P.T. (1995). Manual for the peer relations questionnaire. Adelaide: University of South Australia.

RIVERS, I.; SMITH, P.K. (1994). «Types of bullying behaviour and their correlates». Aggressive Behaviour, 20: 359-68.

SCHLINDER, N. (1997). "Guardians of Disorder: Rituals of Youthful Culture at the Dawn of the Modern Age». A Giovanni, L.; Jean-Claude, S. (eds.). History of Young People in the West. Vol. 1. Ancient and Medieval Rites of Passage. CambridgeLondres: Belknap Press de Harvard UP, p. 240-82.

WiLlis, P. (1981) [1977]. Learning to Labour. How Working Class Kids Get Working Class Jobs. Aldershot: Gower.

- (1996) [1990]. Common Culture. Symbolic Work at Play in the Everyday Cultures of the Young. Milton Keynes: Open University Press.

- (1998) [1990]. Cultura Viva: Una recerca sobre les activitats culturals dels joves. Barcelona: Diputació de Barcelona (Materials de joventut, 10). 